\title{
Development and Preliminary Validation of the Child \& Adolescent Social Cognitions Questionnaire
}

\author{
Eleanor Leigh ${ }^{1,2}$ (D) David M. Clark ${ }^{1}$ \\ Accepted: 16 March 2021 / Published online: 3 April 2021 \\ (c) The Author(s) 2021
}

\begin{abstract}
Negative cognitions play a central role in adolescent social anxiety, and yet there is a lack of empirically validated measures assessing these in detail. This study describes the adaptation of the Child \& Adolescent Social Cognitions Questionnaire (CASCQ) from the adult version of the scale and its preliminary validation in a general adolescent school sample $(\mathrm{N}=671)$. Exploratory and confirmatory factor analysis on split halves of the data indicated two factors, labelled 'negative self-concept' and 'anxious appearance', provided the best fit. Totals and subscales possessed good internal consistency and convergent validity. Findings suggest that the CASCQ is a reliable and valid measure of social anxiety-related cognitions in youth and may be useful for research and clinical purposes. Further examination of the scale with pre-adolescents and clinical samples is warranted.
\end{abstract}

Keywords Social anxiety $\cdot$ Youth $\cdot$ Social anxiety-related cognition $\cdot$ Scale

\section{Introduction}

The question of why some individuals continue to feel anxiety in social and performance situations, even in the absence of negative feedback, is critical for understanding the maintenance of social anxiety disorder (SAD) and for efforts to effectively intervene. Cognitive behavioural models suggest that negative thoughts about oneself and others' reactions in social situations, such as "people will see that I am nervous", "I will blush", and "I am boring", play a central role in the disorder [1-4].

In adults, various scales for assessing such thoughts have been developed, including the Social Cognitions Questionnaire (SCQ) [5]. The SCQ was developed in order to quantify social anxiety-related cognitions [6]. It is comprised of 22 items, each reflecting a common social anxiety-related cognition (e.g. "People will stare at me"). Items are rated on two dimensions: how frequently the thought occurs in social situations, and how strongly the thought is believed.

Eleanor Leigh

eleanor.leigh@psy.ox.ac.uk

1 Department of Experimental Psychology, University of Oxford, Oxford, UK

2 OxCADAT, The Old Rectory, Paradise Square, Oxford OX1 1TW, UK
In adults, the scale has been shown to have good internal consistency [7] and test-retest reliability [8]. A three or four factor structure was indicated in preliminary work of Clark [7], with items loading onto the first factor clustering around the concept of negative self-concept (e.g. "I am unlikeable"), and the second and third factors reflecting concerns about the appearance of anxiety (e.g. "I will be unable to speak" in factor 2 and "I am going red" in factor 3). The fourth factor, reflecting inferiority, accounted for a relatively small amount of variance and had only two strong item loadings. Finally, treatment studies have shown large reductions in frequency and belief ratings on the SCQ over treatment $[9,10]$, indicating that the scale is sensitive to change.

SAD usually begins in childhood or adolescence, with a median age of onset of 13 years [11], and therefore there is theoretical and practical importance to understanding its persistence in youth. Recent research indicates that in young people as in adults, negative social anxiety-related cognitions are associated with social anxiety and appear to be relevant to development and maintenance [12-14]. Furthermore, two treatment studies of Cognitive Therapy for adolescent SAD, a treatment designed specifically to target negative social anxiety-related cognitions and beliefs, found significant reductions in the strength of these by the end of treatment $[15,16]$, consistent with cognitive behavioural accounts of the disorder. 
Surprisingly, only two measures of social-evaluative cognition have been evaluated for use with young people. The Child Automatic Thoughts Questionnaire [17, 18] was designed to measure a range of negative thoughts across anxiety domains, and includes 10 items relating to social threat, for example "other kids are making fun of me". The scale has been shown to be reliable and valid, however as pointed out by Wong and colleagues [19], the scale measures 'in the moment' negative automatic thoughts but it does not assess broader social-evaluative beliefs. The Report of Youth Social Cognitions is a 14-item measure that was developed recently to examine social-evaluative beliefs in youth [19], including items such as "other kids think I'm silly". Whilst the scale was shown to have good psychometric properties [19], it does not include items capturing the particular ways socially anxious youth fear they will behave in social situations (e.g. "I will go red", "I will stumble over my words"). These cognitions are a central feature of cognitive behavioural models of social anxiety [14] and a target for therapies based on these models. In adults, the SCQ measures these cognitions, as well as broader social-evaluative beliefs such as "I am boring", and we think it would be a useful tool to adapt for youth. In particular, it could improve our theoretical understanding of youth social anxiety and aid the delivery of psychological prevention and treatment approaches for SAD in young people.

With this study, we aimed to adapt the SCQ for young people and provide a preliminary examination of its psychometric properties in a school-based sample of UK adolescents. The first aim of the study was to examine the factor structure of the scale. The second aim was to determine preliminary psychometric properties of the scale, in particular internal consistency and construct validity. Construct validity was assessed by examining the associations between the adapted SCQ and scores on a measure of social anxiety, with and without controlling for depression and for generalised anxiety disorder (GAD) symptoms, both of which are strongly associated with social anxiety symptoms [20]. The third aim was to explore and compare scores on the adapted SCQ for older and younger adolescents and for males and females. This is because social anxiety symptoms are known to increase with age during adolescence [21] and to be higher amongst females than males [22] and so we were interested to observe whether scores on the adapted SCQ showed similar gender- and age-related differences.

\section{Method}

\section{Participants}

In total, 671 adolescents aged 11-18 years completed all items of the adapted SCQ as part of their participation in school-based studies of social anxiety in youth. Sample 1 comprised 482 young people in UK school years 7-9 recruited from two non-selective and state-funded secondary schools (aged 11-14 years, mean age $=12.98, \mathrm{SD}=0.87$, 248 [51.45\%] female). Sample 2 comprised 189 young people in years 12 and 13 attending a sixth form college in the UK (aged 16-18 years, mean age $=17.11, \mathrm{SD}=0.72,109$ [57.67\%] female).

\section{Procedures}

The study procedures were in accordance with ethical standards and were approved by the Central University Research Ethics Committee at the University of Oxford (Reference number: R54283/RE001for Sample 1) and the Psychiatry, Nursing and Midwifery Research Ethics Subcommittee at King's College London (HR-18/19-8278; Sample 2). For participants under 16 years of age, written informed assent was obtained from all participants and opt-out consent was provided by participants' parents/guardians. For participants over the age of 16 years, written informed consent was obtained from young people.

Before data collection, the research team explained the study to students during tutor time and information packs were distributed to caregivers and students. All students able to read and write English were encouraged to participate. Data collection took place during school time at least 2 weeks after information about the project had been disseminated. Participants completed a self-report questionnaire pack, including the Social Cognitions Questionnaire adapted for children and adolescents (details below) and measures evaluating social anxiety, anxiety and depression symptoms. For Sample 1, all students in years 7-9 in the two participating schools were invited to participate. 718 students were invited to participate, and the consent rate was $87.2 \%$. For Sample 2, information about the number of students invited was not collected. Of the total 865 participants who participated $(n=657$ from Sample 1 and $n=208$ from Sample 2), 671 had completed all items of the CASCQ. Those who had completed all items of the CASCQ were more likely to have been from Sample 2 (and therefore older) than Sample 1, compared to those who did not complete all items, but there no differences in gender, social anxiety symptoms, or depression symptoms.

\section{Measures}

Child \& Adolescent Social Cognitions Questionnaire (CASCQ) is a self-report questionnaire, with each item corresponding to a common social anxiety-related cognition. All 22 items from the adult Social Cognitions Questionnaire [5] were included in the youth version, with wording adapted to be suitable for children and adolescents. In consultation 
with experts in the field (CC and PW), six additional items were added which were considered to be relevant to young people, for example, "People will be angry with me". A sample of five young people who had recovered from SAD after treatment reviewed the items (original and revised, and the additional items) and rated each one from 0 to 5 on how understandable they were. Revisions improved ratings of all items. The pool of 28 items were all rated $4 / 5$ or $5 / 5$. Respondents are asked to rate how frequently they experience the thought when they are socially anxious, from 1 (never) to 5 (every time), and how much they believe the thought when it occurs, from 0 (not at all) to 100 (totally). Two scores are generated: a mean frequency score and mean belief score. The final 27 item scale is freely available at https://oxcadatresources.com.

The Liebowitz Social Anxiety Scale for Children and Adolescents-Self Report version (LSAS-CA-SR; [23]) is a 24-item self-report scale measuring social anxiety in young people aged 7-18 years old. This scale assesses levels of both fear and avoidance in social and performance situations. Each item has a 0-3 rating represented by 'none', 'mild', 'moderate' and 'severe'. The total score ranges from 0 to 144. The scale has acceptable reliability and validity [23]. The internal consistency in the current sample was $\alpha=0.97$.

The Short Mood and Feelings Questionnaire (SMFQ; [24]) is a 13-item self-report questionnaire designed to assess different aspects of depressive symptoms in young people aged 6-17 years. Each item ranges from 0 (not true) to 2 (true). Total scores were obtained by summing up all the items. This scale has acceptable reliability and validity [25]. The internal consistency in this sample was $\alpha=0.91$.

The child version of the Screen for Anxiety and Related Disorders (SCARED; [26]) is a 41-item self-report questionnaire used to screen for childhood anxiety disorders including general anxiety disorder, separation anxiety disorder, panic disorder, social anxiety disorder, and school phobia. The GAD subscale was used to examine validity in the present study. The scale has good reliability and validity [26, 27]. Internal consistency of the total scale in this sample was $\alpha=0.96$.

\section{Data Analysis}

Data was prepared in SPSS v. 26 and analysis was conducted in $\mathrm{R}$ [28] using the lavaan package [29]. Mean substitution was performed when less than $10 \%$ of items were missing in the LSAS-CA-SR, SCARED and SMFQ questionnaires [30]. At variable level, missing data was low, ranging from 1.19 to $4.32 \%$ (LSAS-CA-SR was missing for $n=8$ participants, SCARED for $n=29$, and SMFQ for $n=20$ ). Little's MCAR test indicating that data was missing completely at random at variable level $(p>0.05)$. For analysis that involved the LSAS-CA-SR, SMFQ and SCARED (i.e. examination of validity), pairwise deletion was used for data missing at variable level.

The factor structure of the CASCQ was examined using a combination of Exploratory Factor Analysis (EFA) and Confirmatory Factor Analysis (CFA) in the general adolescent sample. The sample was split in two randomly (0.6/0.4 ratio). EFA was conducted in the first half of the dataset and then this factor structure was confirmed in the second half using CFA.

The factor structure was examined separately for belief and frequency ratings. The frequency scale generates ordinal data, and so the Ordinary Least Squared method of extraction was used. For the belief scale, the Kolmogorov-Smirnov test showed that the data was normally distributed and so the maximum likelihood method of extraction was used. For both EFA an oblique rotation was used (Oblimin), because we expected the factors to be correlated with each other. To determine the appropriate number of factors to retain we used parallel analysis (for non-normal data in the case of frequency ratings, and normal data in the case of belief ratings) and we examined the scree plot and interpretability of the generated factors. In addition, we examined item loadings, and in line with Guadagnoli and Velicer [31], considered factors on which four or more items had loadings of at least 0.6 as reliable. In terms of evaluating item loadings onto factors, we were guided by Stevens [32], who suggested using a cut-off of 0.4. To test the goodness of fit of the models in the CFA, we examined the Standardized Root Mean Square Residual (SRMR), the Root Mean Square Error of Approximation (RMSEA), the Comparative Fit Index (CFI) and the Tucker Lewis Index (TLI). SRMR values below 0.08 and RMSEA values less than 0.06 indicate a good fit. CFI and TLI values of 0.90 or greater suggest an acceptable fit [33, 34].

The rest of the analysis was undertaken with the whole sample. First, mean scores were calculated for the total score and for the subscales derived from the indicated factor structure. Then, internal consistency of the total score and subscales was assessed with Cronbach's alpha, with alpha greater than 0.70 indicating acceptable consistency and above 0.80 good consistency [35]. To examine construct validity, correlations between the CASCQ totals and subtotals and the LSAS-CASR were examined, before carrying out partial correlations between the CASCQ totals and subtotals and the LSAS-CA$\mathrm{SR}$, controlling for GAD symptoms (from the SCARED) and then for depression symptoms (SMFQ). Finally, we examined age and gender differences in CASCQ-F and CASCQ-B total and subtotal mean scores. 


\section{Results}

\section{Exploratory Factor Analysis: Belief Ratings}

The Kaiser-Meyer-Olkin measure of sampling adequacy $(\mathrm{KMO}=0.98)$ and Bartlett's test of sphericity $\left(\chi^{2}(378)=17853.36, p<0.001\right)$ indicated that the data was suitable for factor analysis. Parallel analysis and examination of the scree plot (Fig. 1; left hand plot) suggested that two factors were appropriate for extraction.

The two-factor solution explained $65 \%$ of the variance, with the first factor explaining $39 \%$ and the second explaining 26\%. Standardized factor loadings are shown in Table 1. Fifteen items loaded onto Factor 1, 13 of these had a loading of $\geq 0.60$. Thirteen items loaded onto Factor 2. Seven of these had a loading of $\geq 0.60$. The two factors were correlated $(r=0.76)$, which supports the idea that the two factors reflect related but not identical concepts. Factor 1 reflects 'negative self-concept' whilst Factor 2 represents 'anxious appearance'.

\section{Exploratory Factor Analysis: Frequency Ratings}

The Kaiser-Meyer-Olkin measure of sampling adequacy $(\mathrm{KMO}=0.97)$ and Bartlett's test of sphericity $\left(\chi^{2}(378)=13,989.21, p<0.001\right)$ indicated that the data was

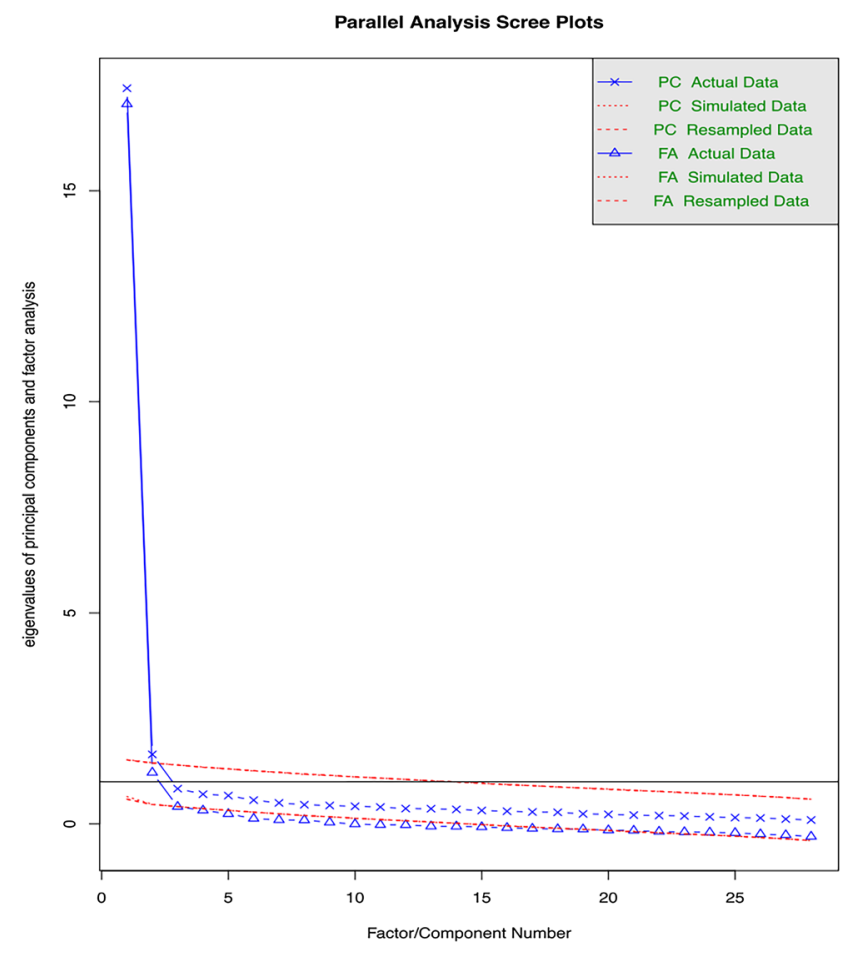

suitable for factor analysis. Parallel analysis suggested that three factors were appropriate for extraction, examination of the scree plot (Fig. 1; right hand plot) indicated that between two and three factors were appropriate, and on examination of the factor loadings and interpretability, a two factor solution was decided upon.

The two factor solution explained $56 \%$ of the variance, with the first factor explaining $35 \%$ and the second explaining $21 \%$. Standardized factor loadings are shown in Table 2. Sixteen items loaded onto Factor 1, twelve with a loading of $\geq 0.60$. Twelve items loaded onto Factor 2. Six of these had a loading of $\geq 0.60$. The two factors were correlated $(r=0.76)$, which supports the idea that the two factors reflect related but not identical concepts. Factor 1 reflects 'negative self-concept' whilst Factor 2 represents 'anxious appearance'.

\section{Confirmatory Factor Analysis}

Based on the EFA, item 25 (“I will get picked on and teased") was dropped from the scale before the CFA, due to instability of loading. This is because the item loaded onto Factor 2 for Belief ratings (loading for Factor 1: 0.38; loading for Factor 2: 0.44), but onto Factor 1 for Frequency ratings (loading for Factor 1: 0.53; loading for Factor 2: 0.14). Loadings from the CFA are shown in Table 3; loadings of all items for the Belief model and the Frequency model were 0.60 or above.

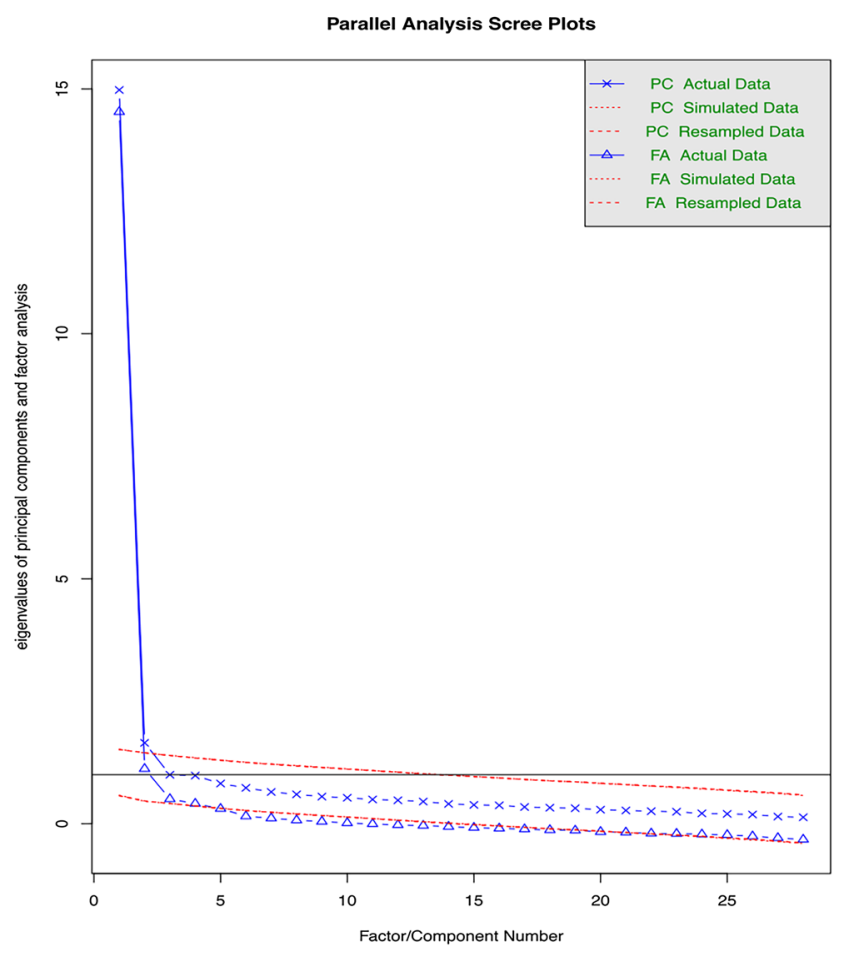

Fig. 1 Scree plots of indicated factors to extract for CASCQ Belief data (left hand plot) and CASCQ Frequency data (right hand plot) 
Table 1 Pattern matrix showing the belief item loadings with a twofactor solution

\begin{tabular}{|c|c|c|c|}
\hline & & Factor 1 & Factor 2 \\
\hline 1 & I will be unable to speak & -0.03 & 0.79 \\
\hline 2 & I am unlikeable & 0.84 & 0.01 \\
\hline 3 & $\begin{array}{l}\text { I am going to tremble or shake uncontrol- } \\
\text { lably }\end{array}$ & -0.04 & 0.85 \\
\hline 4 & People will stare at me & 0.51 & 0.31 \\
\hline 5 & I am being an idiot & 0.75 & 0.08 \\
\hline 6 & People won't want to be friends with me & 0.84 & 0.04 \\
\hline 7 & I will be frozen with fear & -0.09 & 0.93 \\
\hline 8 & I will drop or spill things & 0.17 & 0.61 \\
\hline 9 & I am going to be sick & 0.07 & 0.69 \\
\hline 10 & I am not good enough & 0.92 & -0.08 \\
\hline 11 & I will babble or talk funny & 0.31 & 0.49 \\
\hline 12 & I am not as good as others & 0.97 & -0.12 \\
\hline 13 & I will be unable to concentrate & 0.32 & 0.45 \\
\hline 14 & I will be unable to write properly & 0.07 & 0.73 \\
\hline 15 & People are not interested in me & 0.95 & -0.08 \\
\hline 16 & People won't like me & 0.96 & -0.06 \\
\hline 17 & People will make fun of me & 0.79 & 0.1 \\
\hline 18 & I will sweat/perspire & -0.02 & 0.74 \\
\hline 19 & I am going red & 0.10 & 0.55 \\
\hline 20 & I am weird/different & 0.72 & 0.07 \\
\hline 21 & People will see I am nervous & 0.21 & 0.54 \\
\hline 22 & People think I am boring & 0.63 & 0.2 \\
\hline 23 & I will embarrass myself* & 0.75 & 0.11 \\
\hline 24 & People will be angry with me* & 0.55 & 0.3 \\
\hline 25 & I will get picked on and teased* & 0.38 & 0.44 \\
\hline 26 & I will look stupid* & 0.76 & 0.13 \\
\hline 27 & $\begin{array}{l}\text { I will be forced to do things I don't want } \\
\text { to do* }\end{array}$ & 0.22 & 0.58 \\
\hline 28 & People will laugh at me* & 0.73 & 0.12 \\
\hline
\end{tabular}

Item loadings greater than 0.4 are indicated in bold

*Asterisked items are those items added to the original Social Cognitions Questionnaire when adapting the scale for children and young people

For the Belief ratings, SRMR (0.05), CFI (0.90) and TLI (0.90) were acceptable, but RMSEA was above the recommended threshold (RMSEA $=0.09$ (95\% confidence interval [CI]: 0.086, 0.098)). The fit of the model for the Frequency ratings was better, with all indices in the acceptable range. SRMR was 0.05, RMSEA was 0.05 (95\% CI: 0.042-0.057), and CFI and TLI were both above $0.90(\mathrm{CFI}=0.998$ and $\mathrm{TLI}=0.998)$.

\section{Internal Consistency}

As can be seen in Table 4, internal consistency for the total scores and subscales was good for all frequency and belief scales, ranging from 0.90 to 0.98 .
Table 2 Pattern matrix showing the Frequency item loadings with a two-factor solution

\begin{tabular}{|c|c|c|c|}
\hline & & Factor 1 & Factor 2 \\
\hline 1 & I will be unable to speak & 0.11 & 0.56 \\
\hline 2 & I am unlikeable & 0.92 & -0.09 \\
\hline 3 & $\begin{array}{l}\text { I am going to tremble or shake uncontrol- } \\
\text { lably }\end{array}$ & -0.08 & 0.79 \\
\hline 4 & People will stare at me & 0.44 & 0.34 \\
\hline 5 & I am being an idiot & 0.73 & 0.07 \\
\hline 6 & People won't want to be friends with me & 0.87 & -0.04 \\
\hline 7 & I will be frozen with fear & -0.01 & 0.74 \\
\hline 8 & I will drop or spill things & 0.11 & 0.51 \\
\hline 9 & I am going to be sick & 0.01 & 0.63 \\
\hline 10 & I am not good enough & 0.76 & 0.08 \\
\hline 11 & I will babble or talk funny & 0.26 & 0.47 \\
\hline 12 & I am not as good as others & 0.74 & 0.08 \\
\hline 13 & I will be unable to concentrate & 0.12 & 0.55 \\
\hline 14 & I will be unable to write properly & -0.06 & 0.67 \\
\hline 15 & People are not interested in me & 0.89 & -0.05 \\
\hline 16 & People won't like me & 0.99 & -0.16 \\
\hline 17 & People will make fun of me & 0.76 & 0.1 \\
\hline 18 & I will sweat/perspire & 0.04 & 0.65 \\
\hline 19 & I am going red & 0.16 & 0.46 \\
\hline 20 & I am weird/different & 0.56 & 0.22 \\
\hline 21 & People will see I am nervous & 0.17 & 0.62 \\
\hline 22 & People think I am boring & 0.62 & 0.13 \\
\hline 23 & I will embarrass myself & 0.62 & 0.24 \\
\hline 24 & People will be angry with me & 0.47 & 0.27 \\
\hline 25 & I will get picked on and teased & 0.53 & 0.14 \\
\hline 26 & I will look stupid & 0.69 & 0.14 \\
\hline 27 & $\begin{array}{l}\text { I will be forced to do things I don't want } \\
\text { to do }\end{array}$ & 0.19 & 0.55 \\
\hline 28 & People will laugh at me & 0.65 & 0.15 \\
\hline
\end{tabular}

Item loadings greater than 0.4 are indicated in bold

\section{Convergent Validity}

Convergent validity of the CASCQ was inspected by examining the association between the total and subtotals (for both frequency and belief scales) with self-report measures of social anxiety (LSAS-CA-SR). As expected, and shown in Table 5, each subscale and the totals for both frequency and belief ratings were significantly and positively correlated with the LSAS-CA-SR total $(r s>0.45)$. To rule out the possibility that the association between the CASCQ and social anxiety symptoms is largely due to comorbid GAD or depression symptoms, the correlations between the CASCQ subtotals and totals and LSAS-CA-SR total were repeated first controlling for depression symptoms (Belief Total: partial $\mathrm{r}=0.336, p<0.01$; Frequency Total: partial $\mathrm{r}=0.580$; $p<0.01$ ), and second controlling for GAD symptoms (Belief Total: partial $\mathrm{r}=0.300, p<0.01$; Frequency Total: partial 


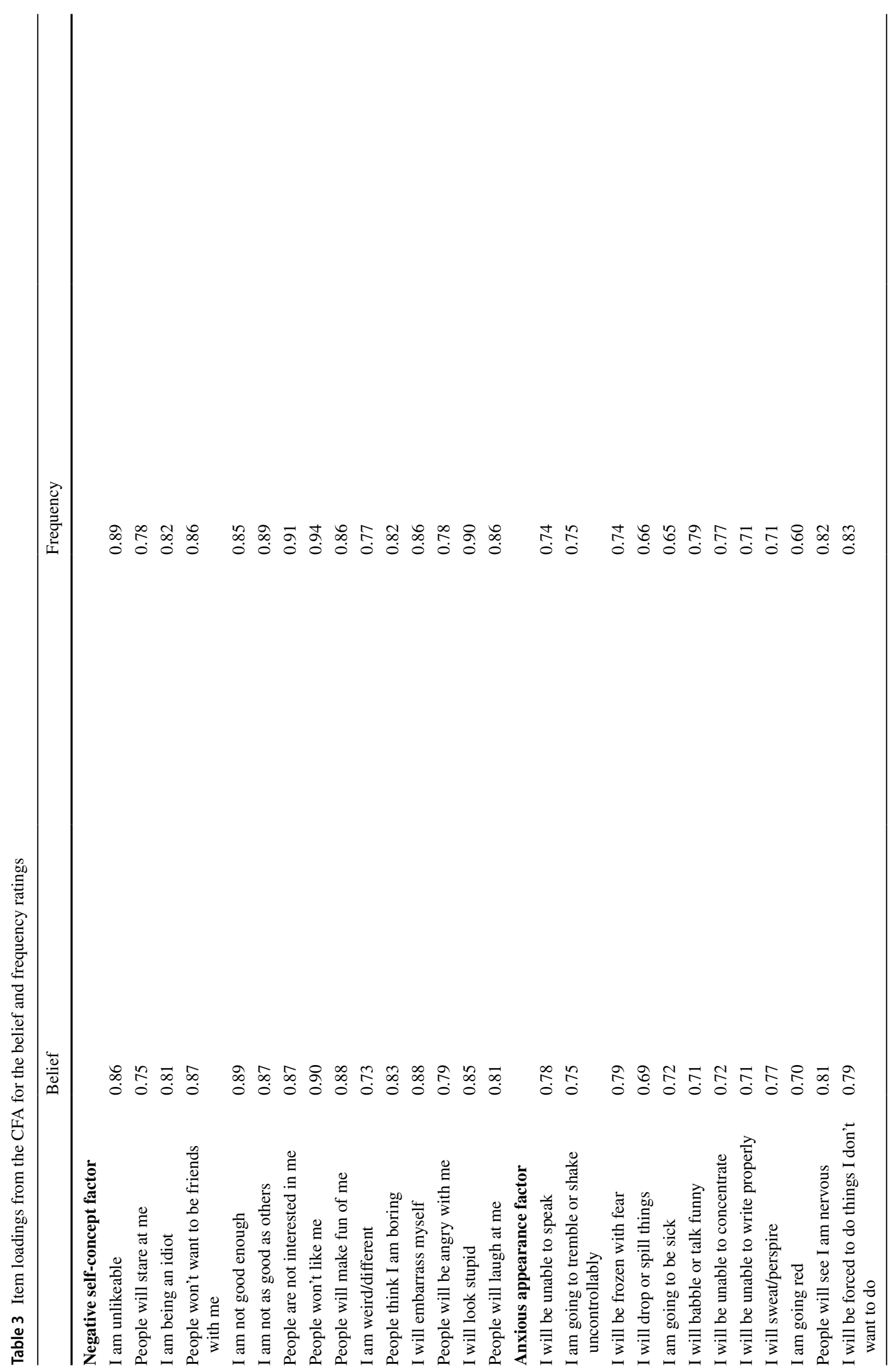




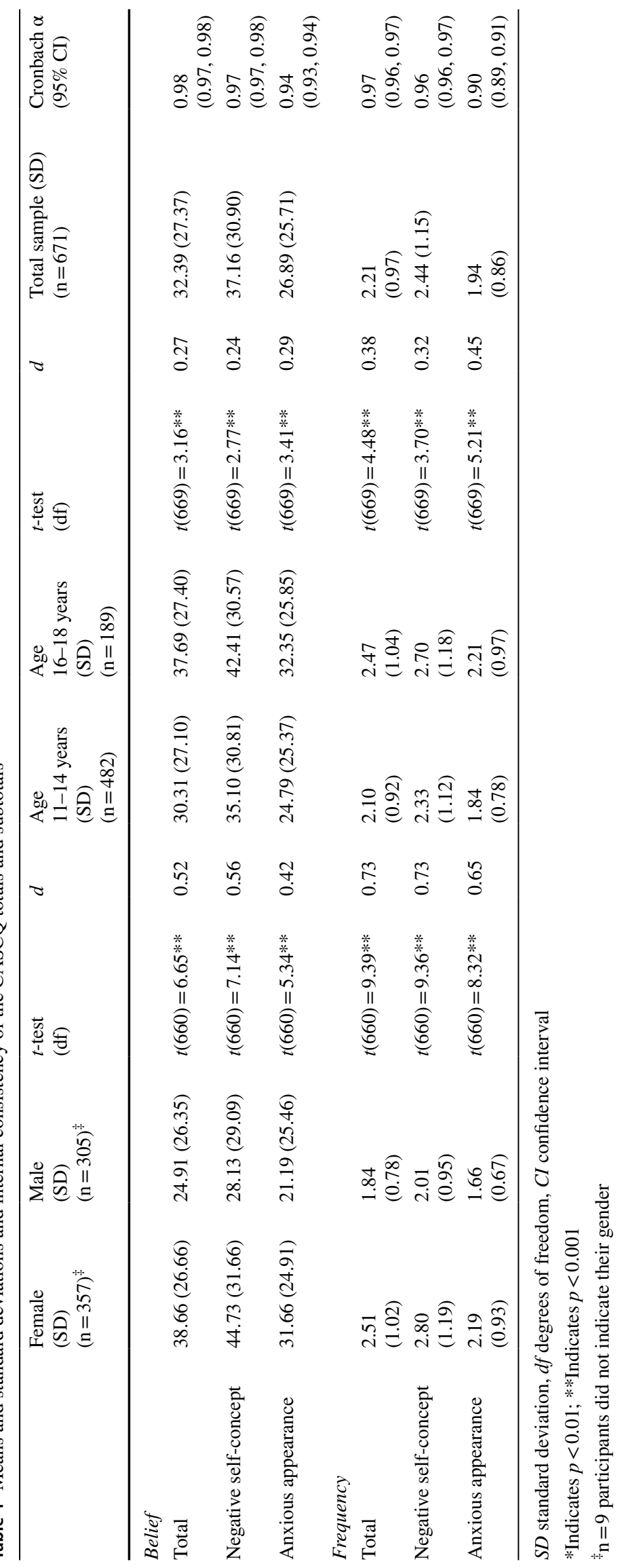


Table 5 Correlations between CASCQ totals and subtotals and social anxiety symptom measure

\begin{tabular}{lllllll}
\hline & CASCQ-B & CASQ-B-N & CASQ-B-A & CASCQ-F & CASQ-F-N & CASQ-F-A \\
\hline LSAS-CA-SR & $\mathbf{0 . 5 6}^{* *}$ & $\mathbf{0 . 5 9 * *}$ & $\mathbf{0 . 4 5}^{* *}$ & $\mathbf{0 . 7 6}^{* *}$ & $\mathbf{0 . 7 4 * *}$ & $\mathbf{0 . 7 0 * *}$ \\
CASCQ-B & & $0.97 * *$ & $0.94 * *$ & $0.71^{* *}$ & $0.68^{* *}$ & $0.66^{* *}$ \\
CASQ-B-N & & & $0.83^{* *}$ & $0.74^{* *}$ & $0.76^{* *}$ & $0.63^{* *}$ \\
CASQ-B-A & & & & $0.57 * *$ & $0.50^{* *}$ & $0.63^{* *}$ \\
CASCQ-F & & & & & $0.97 * *$ & $0.92^{* *}$ \\
CASQ-F-N & & & & & & $0.81^{* *}$ \\
\hline
\end{tabular}

LSAS-CA-SR Leibowitz Social Anxiety Scale for Children and Adolescents Self-Report Version, $C A S C Q$ $B$ Child and Adolescent Social Cognitions Questionnaire Total Belief, CASCQ-B-N Child and Adolescent Social Cognitions Questionnaire Negative Self-Concept Belief, $C A S C Q-B-A$ Child and Adolescent Social Cognitions Questionnaire Anxious Appearance Belief, CASCQ-F Child and Adolescent Social Cognitions Questionnaire Total Frequency, $C A S C Q-F-N$ Child and Adolescent Social Cognitions Questionnaire Negative Self-Concept Frequency, $C A S C Q-F-A$ Child and Adolescent Social Cognitions Questionnaire Anxious Appearance Frequency

*Indicates $p<0.01$; **Indicates $p<0.001$;

Correlations between the LSAS-CA-SR and CASCQ totals and subscales are shown in bold $r=0.486 ; p<0.01)$. Correlations with Belief and Frequency subscale scores also remained significant when controlling for depression symptoms and for GAD symptoms $(p<0.01)$.

\section{Age and Gender Analysis}

As can be seen in Table 4, in the general adolescent samples, girls scored more highly than boys and the older adolescents scored more highly than the younger adolescents on all totals and subtotals of the CASCQ. The same pattern of results is reflected in the LSAS-CA-SR scores, with higher LSAS-CA-SR scores in girls $(p<0.001)$ and older adolescents $(p<0.001)$.

\section{Discussion}

This study provides a preliminary psychometric analysis of the Social Cognitions Questionnaire [6], adapted for children and adolescents (CASCQ). We found support for the reliability and validity of the scale in a general sample of UK adolescents.

We were initially interested in examining the factor structure of the scale. We undertook EFA in a random half of the sample and identified a two-factor solution for both belief and frequency ratings. Item loadings were strong and broadly consistent across the two scoring forms. The factor structure was then supported in a CFA undertaken in the second half of the sample. The fit was acceptable for the frequency ratings. Whilst certain fit indices were more marginally acceptable for the belief ratings, we note that all item loadings remained high. Inspecting the item loadings, we interpreted one factor as 'negative selfconcept' and the other as 'anxious appearance'. Example items loading on the 'negative self-concept' factor include "people will think I am boring" and "I am unlikeable". Example items loading on the 'anxious appearance' factor include "I will be unable to speak" and "I am going red". The correlation between the two factors for the Belief rating was $r=0.83$ and $r=0.81$ for the Frequency rating. This suggests that the two factors show moderate overlap as we would expect, but they seem to measure slightly different aspects of social anxiety-related cognitions.

Although here we identified two factors compared to the three/four specified in the factor analysis undertaken by Clark [7] in the adult SCQ, there is notable overlap in the apparent underlying constructs. For example, the first factor of the adult SCQ relates to negative self-concept, as we found here, and the second and third factors reflected anxious appearance, as our second factor did. The two factors are consistent with leading cognitive behavioural accounts of social anxiety $[1,3,4]$. These accounts align to suggest that unconditional negative beliefs about the self, such as "I'm unlikeable", lie at the heart of social anxiety, as do cognitions related to social performance deficits and observability of anxious feelings. The finding is important as it supports the suggestion that adult cognitive models of social anxiety, such as that of Clark and Wells [4] are also relevant to youth [12].

Typically measures of beliefs and cognitions in youth anxiety have assessed either the frequency or the strength of the belief. We believe the CASCQ is unusual in measuring both frequency and belief ratings. Each shows substantial correlations with social anxiety. The correlation between frequency and belief $(r=0.71)$ suggests approximately $50 \%$ shared variance. Although the two are interrelated, it seems possible that they index slightly different features of cognition and it is therefore worth retaining both. In the present sample the correlation between social anxiety and frequency ratings is somewhat higher than 
between social anxiety and belief ratings. It would be interesting to examine whether this remains so in a clinical sample.

Encouragingly, the scale appears to be reliable, with excellent internal consistency for all the totals and subtotals. Examination of the patterns of association suggest that as expected, the CASCQ was positively and significantly correlated with a measure of social anxiety, but importantly the correlations with social anxiety symptoms persisted when controlling for depression symptoms and for generalised anxiety symptoms. This indicates that the observed associations are not an artefact of the relationship between symptoms of either depression or generalised anxiety and negative social anxiety-related cognitions.

The finding that socially anxious cognitions were more frequent and strongly held amongst girls compared to boys in our general population sample was as expected given the consistent finding of higher levels of social anxiety in females [36]. Similarly, the finding of an age effect was also expected, with higher levels of socially anxious cognitions in older, compared to younger, adolescents. Epidemiological studies consistently show increasing levels of social anxiety from early adolescence though to early adulthood [36].

The study has a number of limitations. The CASCQ was designed for children and adolescents, but we only recruited adolescents. It will be important to see how the measure performs with pre-adolescents. Our sample was recruited from schools. Future studies with clinic-recruited young people, including those with and without SAD, will be informative in terms of psychometric properties of the scale in a clinical population as well as its sensitivity and specificity. Participants completed the CASCQ at one time point only, and so we do not know how reliable the measure is over time. Finally, we note that our measures were exclusively self-report. We took this decision given the centrality of the internal veracity of these cognitions (rather than objective reality) to the persistence of social anxiety in cognitive behavioural accounts, but the inclusion of parent and/ or teacher report symptom measures would be informative.

The present study describes the development of a measure of social anxiety-related cognitions for children and young people, the CASCQ and evaluation of its psychometric properties. With increasing interest in the adaptation of cognitive behavioural treatments for SAD, such as Cognitive Therapy for youth that have been proven to be highly effective for adult SAD [37], comes the need for questionnaires that measure key treatment targets. Here, we hope to have developed a tool that will be useful to both clinicians and researchers.

\section{Summary}

In this paper, we describe the adaptation of the Child \& Adolescent Social Cognitions Questionnaire (CASCQ) from the adult version of the scale and its preliminary validation in a general adolescent school sample. Factor analysis indicated two factors provided best fit, reflecting 'negative self-concept' and 'anxious appearance'. We found evidence for good internal consistency and convergent validity for totals and subtotals. Findings from this preliminary study suggest that the CASCQ is a reliable and valid measure of social anxiety-related cognitions in youth and may be useful for research and clinical purposes.

Acknowledgements We would like to thank Kenny Chiu and Rachel Evans for data collection, Cathy Creswell and Polly Waite for their input on adapting the scale, and all participating schools and young people.

Funding Eleanor Leigh is funded by the Wellcome Trust clinical research training fellowship $(102176 / Z / 13 / Z)$. David M. Clark is funded by the Wellcome Trust (WT069777) and National Institute for Health Research (NF-SI-0512-10132).

\section{Declarations}

Conflict of interest DMC is the author of the Social Cognitions Questionnaire.

Ethical Approval All procedures were in accordance with the ethical standards of the institutional research committee and with the 1964 Helsinki declaration and its later amendments or comparable ethical standards.

Open Access This article is licensed under a Creative Commons Attribution 4.0 International License, which permits use, sharing, adaptation, distribution and reproduction in any medium or format, as long as you give appropriate credit to the original author(s) and the source, provide a link to the Creative Commons licence, and indicate if changes were made. The images or other third party material in this article are included in the article's Creative Commons licence, unless indicated otherwise in a credit line to the material. If material is not included in the article's Creative Commons licence and your intended use is not permitted by statutory regulation or exceeds the permitted use, you will need to obtain permission directly from the copyright holder. To view a copy of this licence, visit http://creativecommons.org/licenses/by/4.0/.

\section{References}

1. Rapee RM, Heimberg RG (1997) A cognitive-behavioral model of anxiety in social phobia. Behav Res Ther 35(8):741-756

2. Heimberg RG, Brozovich FA, Rapee RM (2010) A cognitivebehavioral model of social anxiety disorder: update and extension. In: Hofmann SG, DiBartolo PM (eds) Social anxiety: clinical, developmental, and social perspectives. Academic Press, Boston, MA, pp 395-422 
3. Hofmann SG (2007) Cognitive factors that maintain social anxiety disorder: a comprehensive model and its treatment implications. Cogn Behav Ther 36(4):193-209

4. Clark DM, Wells A (1995) A cognitive model of social phobia. In: Heimberg $\mathrm{G}$ et al (eds) Social phobia: diagnosis, assessment, and treatment. The Guilford Press, New York, pp 69-93

5. Wells A, Stopa L, Clark DM (1995) Social anxiety process measures. Available from: https://oxcadatresources.com.

6. Clark DM (2003) Social anxiety process measures. Available from: https://oxcadatresources.com.

7. Clark DM (2005) Three questionnaires for measuring central constructs in the cognitive model of social phobia. King's College London, London

8. Tanner RJ, Stopa L, De Houwer J (2006) Implicit views of the self in social anxiety. Behav Res Ther 44(10):1397-1409

9. Thew GR et al (2019) Internet-based cognitive therapy for social anxiety disorder in Hong Kong: therapist training and dissemination case series. JMIR Form Res 3(2):e13446-e13446

10. Stott R, Wild J, Grey N, Liness S, Warnock-Parkes E, Commins S, Readings J, Bremner G, Woodward E, Ehlers A, Clark DM (2013) Internet-delivered cognitive therapy for social anxiety disorder: a development pilot series. Behav Cogn Psychother 41(4):383-397

11. Beesdo-Baum $\mathrm{K}$ et al (2012) The natural course of social anxiety disorder among adolescents and young adults. Acta Psychiatr Scand 126(6):411-425

12. Leigh E, Clark DM (2018) Understanding social anxiety disorder in adolescents and improving treatment outcomes: applying the cognitive model of Clark and Wells (1995). Clin Child Fam Psychol Rev. https://doi.org/10.1007/s10567-018-0258-5

13. Halldorsson B, Creswell C (2017) Social anxiety in pre-adolescent children: what do we know about maintenance? Behav Res Ther 99(Supplement C):19-36

14. Wong QJJ, Rapee RM (2016) The aetiology and maintenance of social anxiety disorder: a synthesis of complimentary theoretical models and formulation of a new integrated model. J Affect Disord 203:84-100

15. Ingul JM, Aune T, Nordahl HM (2014) A randomized controlled trial of individual cognitive therapy, group cognitive behaviour therapy and attentional placebo for adolescent social phobia. Psychother Psychosom 83(1):54-61

16. Leigh E, Clark DM (2016) Cognitive therapy for social anxiety disorder in adolescents: a development case series. Behav Cogn Psychother 44(1):1-17

17. Schniering CA, Lyneham HJ (2007) The Children's Automatic Thoughts Scale in a clinical sample: psychometric properties and clinical utility. Behav Res Ther 45(8):1931-1940

18. Schniering CA, Rapee RM (2002) Development and validation of a measure of children's automatic thoughts: the children's automatic thoughts scale. Behav Res Ther 40(9):1091-1109

19. Wong QJJ et al (2018) Development and validation of a measure of maladaptive social-evaluative beliefs characteristic of social anxiety disorder in youth: the Report of Youth Social Cognitions (RYSC). Psychol Assess 30(7):904-915

20. Creswell C, Waite P, Hudson J (2020) Practitioner review: anxiety disorders in children and young people-assessment and treatment. J Child Psychol Psychiatry 61(6):628-643
21. Westenberg PM et al (2007) Social evaluation fear in childhood and adolescence: normative developmental course and continuity of individual differences. Br J Dev Psychol 25(3):471-483

22. Asher M, Aderka IM (2018) Gender differences in social anxiety disorder. J Clin Psychol 74(10):1730-1741

23. Masia-Warner C et al (2003) The Liebowitz Social Anxiety Scale for children and adolescents: an initial psychometric investigation. J Am Acad Child Adolesc Psychiatry 42(9):1076-1084

24. Angold A et al (1995) The development of a short questionnaire for use in epidemiological studies of depression in children and adolescents. Int J Methods Psychiatr Res 5:237-249

25. Thabrew $\mathrm{H}$ et al (2018) Validation of the Mood and Feelings Questionnaire (MFQ) and Short Mood and Feelings Questionnaire (SMFQ) in New Zealand help-seeking adolescents. Int J Methods Psychiatr Res 27(3):e1610

26. Birmaher B et al (1997) The screen for child anxiety related emotional disorders (SCARED): scale construction and psychometric characteristics. J Am Acad Child Adolesc Psychiatry 36(4):545-553

27. Birmaher B et al (1999) Psychometric properties of the Screen for Child Anxiety Related Emotional Disorders (SCARED): a replication study. J Am Acad Child Adolesc Psychiatry 38(10):1230-1236

28. R Core Team (2019) R: a language and environment for statistical computing. R Foundation for Statistical Computing, Vienna, Austria

29. Rosseel Y (2012) lavaan: an R package for structural equation modeling. J Stat Softw 48(2):1-36

30. Peng $\mathrm{C}$ et al (2006) Advances in missing data methods and implications for educational research. Real data analysis. Information Age Publishing, Charlotte, NC, pp 31-78

31. Guadagnoli E, Velicer WF (1988) Relation of sample size to the stability of component patterns. Psychol Bull 103(2):265

32. Stevens JP (2012) Applied multivariate statistics for the social sciences. Routledge, London

33. Hu L-T, Bentler PM (1999) Cutoff criteria for fit indexes in covariance structure analysis: conventional criteria versus new alternatives. Struct Equ Model 6(1):1-55

34. Brown TA (2015) Confirmatory factor analysis for applied research. Guilford Publications, New York

35. George D, Mallery P (2016) Reliability analysis. IBM SPSS statistics 23 step by step. Routledge, London, pp 245-256

36. Westenberg PM et al (2009) A prepared speech in front of a prerecorded audience: subjective, physiological, and neuroendocrine responses to the Leiden Public Speaking Task. Biol Psychol 82:116-124

37. Mayo-Wilson E et al (2014) Psychological and pharmacological interventions for social anxiety disorder in adults: a systematic review and network meta-analysis. Lancet Psychiatry 1(5):368-376

Publisher's Note Springer Nature remains neutral with regard to jurisdictional claims in published maps and institutional affiliations. 